\title{
A natural rubber waste derived surfactant for high internal phase emulsion templating of poly(dicyclopentadiene)
}

Viktor Schallert and Christian Slugovc*

V. Schallert, Prof. C. Slugovc

Institute for Chemistry and Technology of Materials, Graz University of Technology, Stremayrgasse 9, A 8010 Graz, Austria and Christian Doppler Laboratory for Organocatalysis in Polymerization; Stremayrgasse 9, A 8010 Graz, Austria

E-mail: slugovc@tugraz.at

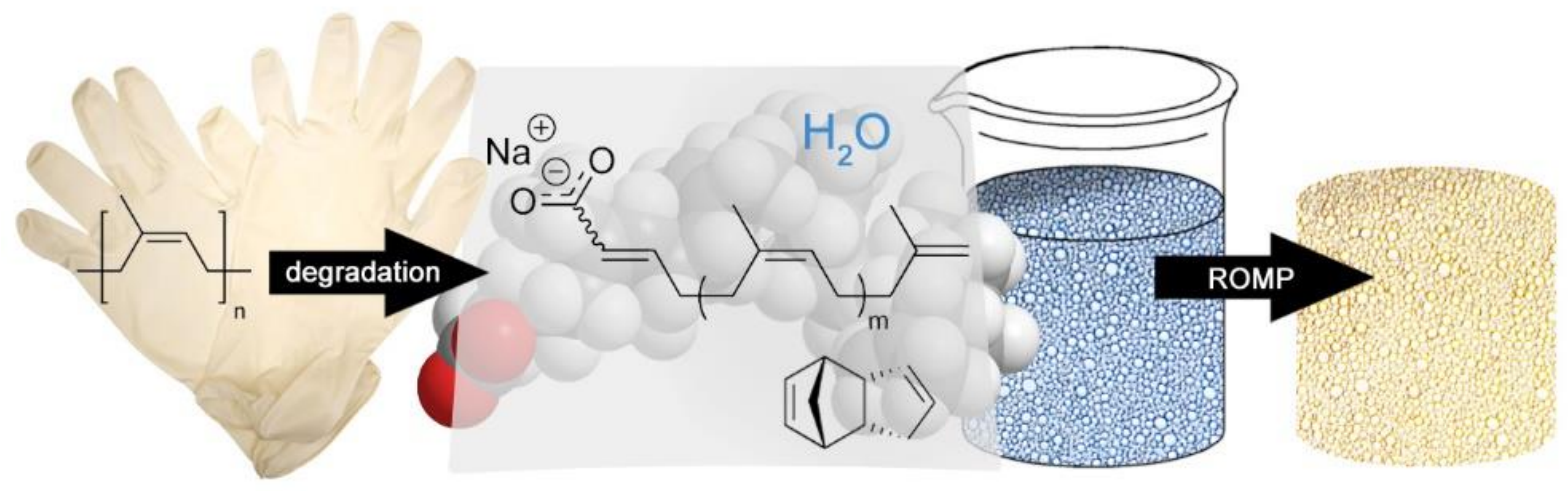

The use of a surfactant derived from the degradation of natural rubber gloves via crossmetathesis with methyl acrylate and subsequent saponification of the ester group for the stabilization of water in dicyclopentadiene high internal phase emulsions is described. The versatility of the resulting high internal phase emulsion was demonstrated by polymerizing the continuous dicyclopentadiene phase via Ring-opening Metathesis Polymerization yielding macroporous poly(dicyclopentadiene) foams with a porosity of $82 \%$. The use of the ionic surfactant allows for the preparation of foams, which are resistant to absorb water. This property was hitherto not accessible with protocols involving the use of non-ionic surfactants commonly employed in emulsion templating of polymers. 


\section{Introduction}

Natural rubber (NR) is an agricultural product produced in about 13.3 million metric tons per year (numbers from 2017). ${ }^{[1]} \mathrm{NR}$ is used as feedstock in e.g. chemical, transportation or medical industries for the production of thermosetting materials, which are typically incinerated at the end of their utilization period. In the last years, efforts to reclaiming ${ }^{[2,3]}$ and to chemically recycle NR based products emerged as a potentially more sustainable use of the resource. ${ }^{[4,5]}$ In particular, Cross Metathesis $(\mathrm{CM})$ based methods are considered a promising way for converting NR waste into feedstock for the chemical industry. ${ }^{[6,7]}$ Various protocols for obtaining chain-end functionalized oligomeric 1,4-cis-isoprenes from NR and in further course also from (vulcanized) NR based products were disclosed in the past. ${ }^{[8,9,10,11,12,13]} \mathrm{We}$ contributed to these endeavors by demonstrating the potential of electron deficient olefins, namely acrylates, as CM-partners in the degradation of NR based goods. The reaction allows for the preparation of oligomers containing $\alpha, \beta$-unsaturated ester moieties as one end-group, which was used for a subsequent [4+2] cycloaddition with cyclopentadiene. Ring-opening metathesis polymerization (ROMP) of the resulting norbornene bearing oligomers finally yielded polymers with similar thermal characteristics as natural rubber (Fig. 1). ${ }^{[14]}$ Based on these results, we herein strive for exploring further applications of semi-telechelic oligomeric 1,4-cis-isoprenes containing $\alpha, \beta$-unsaturated ester end-groups. Specifically, we aim at saponification of the ester group. We hypothesized that amphiphilic molecules with a low hydrophilic-lipophilic balance (HLB) suited for stabilization of high internal phase emulsions (HIPEs) might be accessible by this approach.

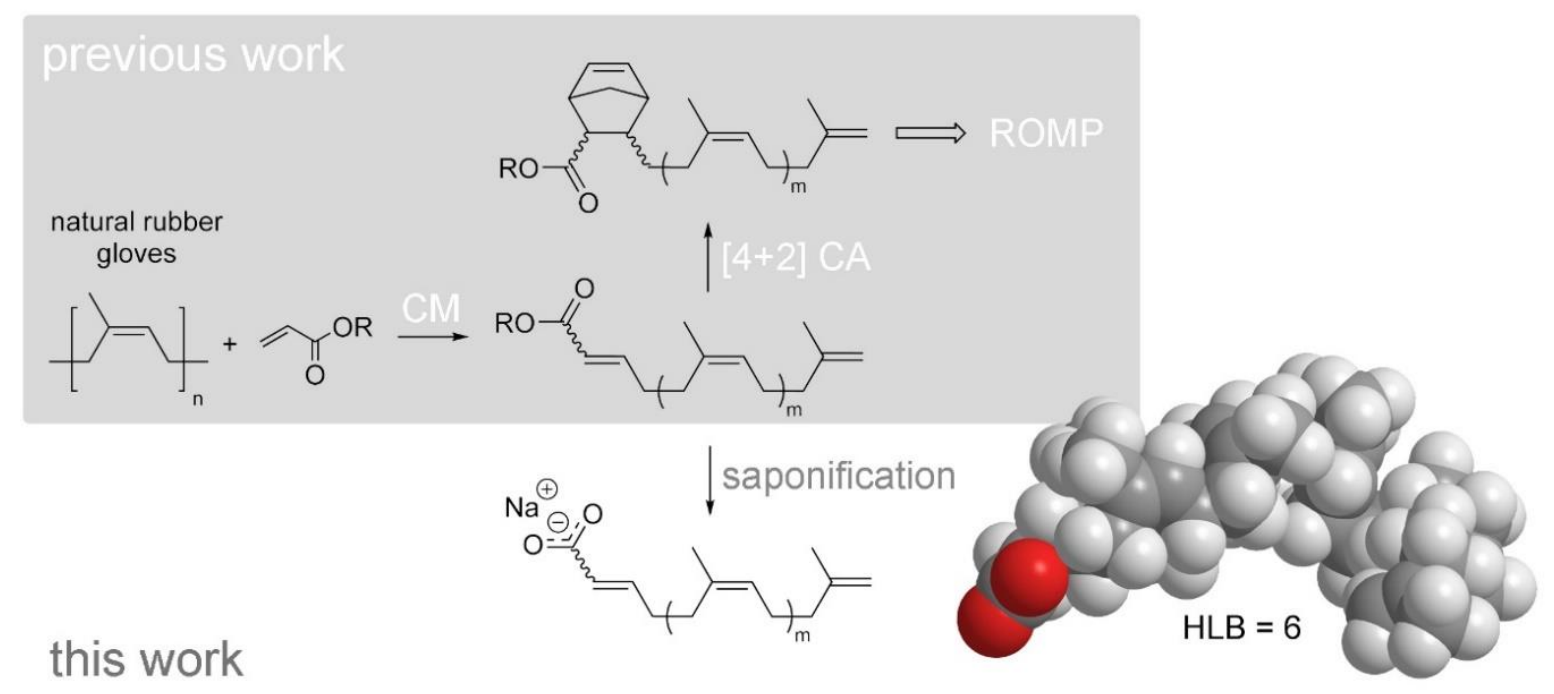

Figure 1. Previous work on natural rubber degradation and the basic idea for the research presented here. The space-fill model shows a saponified oligomer with $m=9$ featuring a HLB of approx. 6 (as the sodium salt, calculated according of Davies ${ }^{[15]}$ ) 
HIPEs are usually stabilized by non-ionic surfactants and can be used to prepare macroporous polymer foams by curing the continuous phase consisting of monomers. ${ }^{[16,17]}$ Such porous materials are often named polymerized HIPEs, abbreviated as poly(HIPE)s. Typically, materials with open-porous highly interconnected architectures are obtained, which find applications in many different fields. ${ }^{[16,17]}$ polyHIPEs are prepared by many polymerization techniques but above all (free) radical polymerization of styrenes or electron deficient olefins is used. ${ }^{[16]}$ One of the more exotic polymerization techniques for curing HIPEs, first introduced by Deleuze et al., ${ }^{[18,19]}$ is ROMP. ROMP became an important technique, because it enables the preparation of polyHIPEs from cheap and readily available dicyclopentadiene (DCPD), which exhibit unique and favorable mechanical properties usually not associated with this class of porous materials. ${ }^{[20]}$ pDCPD based foams combine high strength with high toughness. ${ }^{[21,22,23,24]}$ In other words, the porous materials are stiff and ductile at the same time (the Young's modulus of a foam with $80 \%$ porosity is about $116 \mathrm{MPa}$, the modulus of toughness is around $\left.600 \mathrm{~kJ} / \mathrm{m}^{3}\right) .{ }^{[25]}$ Moreover, the high unsaturation of the polymer scaffold allows for a huge variety of chemistries suited for post-polymerization functionalization of pDCPD foams. ${ }^{[21,26,27,28,29,30]}$ The combination of these two features led to the use of emulsion templated pDCPD foams as separators in Li-ion batteries, ${ }^{[31]}$ as templates for making porous oxides, ${ }^{[32,33]}$ for making composite materials ${ }^{[32,33,34,35,36,37]}$ and carbon foams, ${ }^{[38]}$ for stabilization of enzymes ${ }^{[39]}$ or for detoxification of nerve gases. ${ }^{[28]}$ All these HIPE templated pDCPD foams were prepared with the aid of non-ionic surfactants. Herein we wish to evaluate the principal feasibility of preparing HIPE templated pDCPD foams with an anionic surfactant.

\section{Results and Discussion}

\section{Preparation of the amphiphile}

The published procedure for the degradation of NR glove waste ${ }^{[14]}$ uses finely chopped gloves as the starting material resulting in a heterogeneous reaction mixture. As the catalyst the relatively expensive oxygen chelated compound M510 (formerly known as M51) and ethyl acrylate were used. When performing the reaction with $0.5 \mathrm{~mol} \%$ catalyst (in respect to double bonds in NR) the desired oligomer $\mathbf{1}$ with $\mathrm{m}=3.2$ ( $\mathrm{m}$ is the average number of NR repeating units, Scheme 1) was obtained. Furthermore, the reaction mixture contained diethyl fumarate and incompletely degraded natural rubber parts. In this work, it was attempted to reduce the cost of the degradation step by using the cheaper catalyst $\mathbf{M 2 0 2}$ (formerly known as M2) and by lowering its loading. Key for achieving this task was to thermomechanically predegrade the NR gloves. ${ }^{[2]}$ Upon stirring finely chopped NR glove waste dispersed in toluene at $200 \mathrm{rpm}$ for 
$48 \mathrm{~h}$ at $110{ }^{\circ} \mathrm{C}$ resulted in a polyisoprene solution, which was separated from insoluble parts by centrifugation followed by filtration. The resulting polyisoprene is obtained in $75 \%$ yield and is characterized by a distinctly reduced molecular weight $\left(\mathrm{M}_{\mathrm{n}}=1300 \mathrm{~g} / \mathrm{mol}\right.$, according to SEC in THF relative to poly(styrene)). The solution in toluene can be directly used for the CM step. Upon addition of 5 equiv. methyl acrylate and $0.1 \mathrm{~mol} \%$ of $\mathbf{M 2 0 2}$ (in respect to double bonds in polyisoprene) and heating of the reaction mixture for $22 \mathrm{~h}$ the desired degradation product 1 (with $\mathrm{m}=6.5$ ) was obtained, after column chromatography, in 67\% yield.
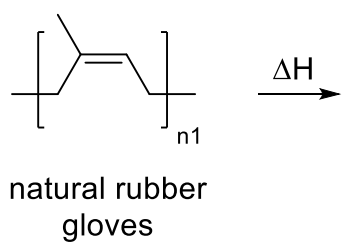
gloves

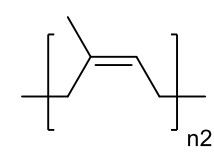

thermally pre-degraded $\mathrm{n} 2<\mathrm{n} 1$

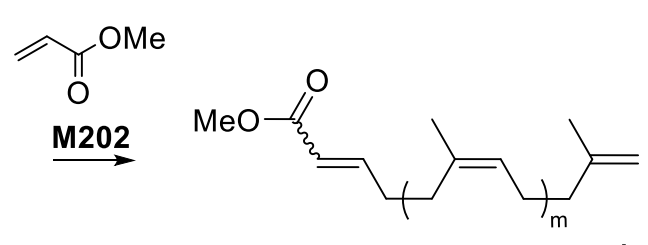

1 $\mathrm{NaOH} \downarrow \mathrm{EtOH}$

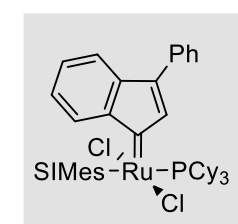

M202

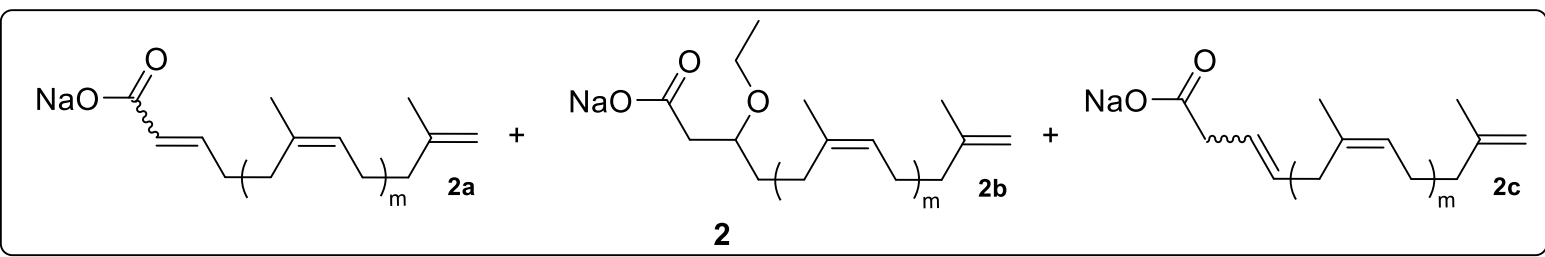

\section{Scheme 1.}

The compound mixture 1 was characterized using ${ }^{1} \mathrm{H}$ - and ${ }^{13} \mathrm{C}-\mathrm{NMR}$-spectroscopies and results match with literature (Fig. S2). ${ }^{[14]}$ Characteristic peaks in the ${ }^{1} \mathrm{H}-\mathrm{NMR}$ comprise a doublet of triplet at $6.94 \mathrm{ppm}$ and a doublet at 5.82 (protons of the electron deficient double bond in $\mathrm{E}$ configuration) and a broadened signal from 5.30-5.00 ppm (olefinic protons of the oligoisoprene). The signal for methyl ester group gives rise to a singlet at $3.72 \mathrm{ppm}$.

The oligomer mixture $\mathbf{1}$ was then saponified by dissolving it in ethanol, adding sodium hydroxide and heating the reaction mixture for $4 \mathrm{~h}$ at $75^{\circ} \mathrm{C}$. Volatiles were removed in vacuum and the residue was extracted with cyclohexane. The cyclohexane solution was washed with water and subsequently dried. Upon removal of cyclohexane and drying in vacuum, the product mixture 2 was obtained in $72 \%$ yield. Infrared spectrometry confirmed the presence of sodium carboxylate groups $\left(v=1554 \mathrm{~cm}^{-1}\right)$, the ester's $\mathrm{C}=\mathrm{O}$ stretch vibration $\left(\nu=1728 \mathrm{~cm}^{-1}\right)$ characteristic for 1 was no longer observed (Fig. S4). In the ${ }^{1} \mathrm{H}-\mathrm{NMR}$ spectrum of 2 (in $\mathrm{CDCl}_{3}$ ) the signal for the methyl ester group was missing. The average number of NR repeating units $\mathrm{m}$ was found to be approx. 7. However, the integrals of the protons of the electron deficient double bonds (now at $7.07 \mathrm{ppm}$ and $5.86 \mathrm{ppm}$ ) were significantly smaller (approx. $60 \%$ of the theoretical value) than expected from the integral of the terminal vinylene group peaking at $4.69 \mathrm{ppm}$. This observation points either to a partly consumption of the double bond by another 
reaction or to an aggregation of $\mathbf{2} \mathbf{a}$ in solution. The latter possibility could be ruled out because upon addition of 1 drop of trifluoroacetic acid to the NMR sample (i.e. converting the sodium carboxylate to the corresponding carboxylic acid) the observed discrepancy remained unchanged. Having a closer look to the NMR spectra suggests that side reactions occurred. Indications for an $o x a$-Michael reaction with ethanol as well as double bond migration could be retrieved. Two multiplets peaking at 3.72 and $3.56 \mathrm{ppm}$ assigned to the diastereotopic methylene group of an ethyl ether derivative are representative for the oxa-Michael derived byproduct $\mathbf{2 b}$, present in approx. $30 \%$. The assignment is based on a model compound derived from methyl crotonate, which was saponified using the same protocol as used for 1 (Fig. S7). Furthermore, multiplets at 3.08 and $2.77 \mathrm{ppm}$ provide some evidence for a deconjugative isomerization of the enoate group leading to $\mathbf{2 c},{ }^{40}$ i.e. double bond migration from $\alpha, \beta$ to $\beta, \gamma$ position occurred as the second side reaction in about $10 \%$. As both side reactions hardly change the HLB value of the potential surfactant, the product mixture was used for emulsion preparation.

\section{Preparation and characterization of pDCPD foams}

The solubility of $\mathbf{2}$ (with $\mathrm{m} \approx 7$ ) in cyclohexane was already considered promising and indeed 2 is easily soluble (at least up to $10 \mathrm{w} \%$ ) in DCPD. Accordingly, an emulsion was prepared by slowly adding four parts of a $0.25 \mathrm{M} \mathrm{NaCl}$ solution in water to one part of a solution containing $6.5 \mathrm{w} \% 2$ and $93.5 \mathrm{w} \%$ DCPD under constant mechanical stirring at $400 \mathrm{rpm}$ at room temperature. The addition of the aqueous phase was accomplished in $10 \mathrm{~min}$ and stirring was continued for further $50 \mathrm{~min}$.

A sample of the emulsion was placed on a microscope slide, covered with a slip and investigated using optical microscopy, revealing the presence of a water in DCPD high internal phase emulsion with water droplet diameters of approx. $6.5 \mu \mathrm{m}$. The emulsion's stability was further studied by placing $4 \mathrm{~mL}$ in an oven operated at $80^{\circ} \mathrm{C}$ and taking samples after 30,60 and 90 min. Optical microscopy revealed a slow increase of the average droplet diameter and the droplet diameter distribution over time (Fig. 2). After 90 min an average droplet diameter of approx. $10 \mu \mathrm{m}$ was reached. These findings indicate a sufficient emulsion stability for curing the emulsion templated DCPD phase by the usually used protocol operating at $80^{\circ} \mathrm{C}^{[23,25]}$ Moreover, it is to note, that no sign of creaming or sedimentation could be observed when the emulsion is stored at $80{ }^{\circ} \mathrm{C}$ for 4 days.

The polymer foams were prepared by quickly adding a solution of the initiator $\mathbf{M 2 0 2}^{[41]}(66.7$ ppm in respect to DCPD) in minor amounts of toluene to the emulsion under vigorous stirring. 
The slightly pink emulsion was then poured into Teflon molds and placed in an oven operated at $80^{\circ} \mathrm{C}$ for $3 \mathrm{~h}$. Afterwards the samples were cooled to room temperature, demolded and subsequently submersed in acetone for $15 \mathrm{~min}$. The specimens were dried under vacuum at room temperature until constant weight was reached.

Foam specimens exhibited a volume shrinkage of about $2 \%$ (percentage of the specimens volume compared to the molds volume) and featured apparent densities in the range from 0.20 to $0.21 \mathrm{~g} \cdot \mathrm{mm}^{-3}$ (retrieved from dividing the mass of the specimens by their volume). The skeleton density determined to be approx. $1.08 \mathrm{~g} \cdot \mathrm{mm}^{-3}$ (calculated from mass and assuming $80 \%$ porosity). The porosities of the specimens ranged in between $81 \%$ and $82 \%$ and were very close to the nominal porosity of $80 \%$ (calculated from mass increase by immersion of $n$-pentan1-ol) taking the volume change into consideration. The morphology of the foams was studied by Scanning Electron Microscopy and the typical throughout open polyHIPE morphology characterized by the presence of voids interconnected with windows was found (Fig. 3). The median void size was about $12 \mu \mathrm{m}$ and window sizes were in the range of 1-2 $\mu \mathrm{m}$. The void size distribution was distinctly higher than in the uncured emulsion stored for 90 min at $80^{\circ} \mathrm{C}$. Void an window sizes are comparable to a pDCPD foam prepared from an emulsion stabilized with $1.5 \mathrm{w} \%$ Pluronics L121 under similar conditions. ${ }^{[32]}$ From infrared spectroscopy it was revealed that only minor amounts of 2 remained in the foam (Fig. S10).

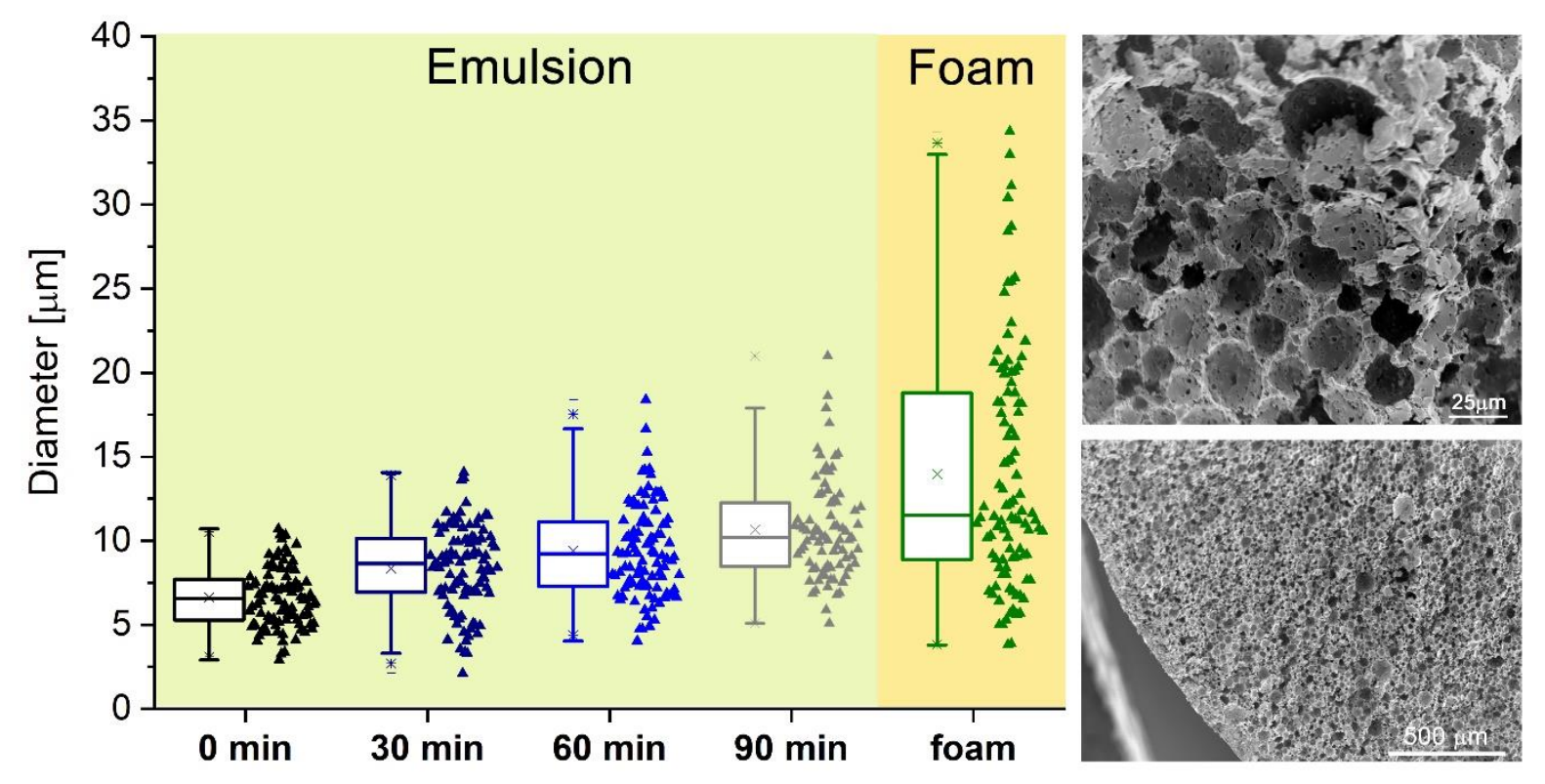

Figure 2. left) box-whisker/bee swarm plot of droplets diameters of the w/o emulsion directly after preparation at $23{ }^{\circ} \mathrm{C}$ and after 30,60 and $90 \mathrm{~min}$ at $80^{\circ} \mathrm{C}$ as well as the void diameter distribution of the cured emulsion (median: horizontal line in the box; quartiles: upper and lower limit of the box, the boxes represent a restricted area where half of the overall values are included; whiskers: 1.5.IQR); right) scanning electron micrographs of the (oxidized) foams at two different magnifications. 
This is remarkable considering the simple and short purification procedure and is in stark contrast to the behavior of Pluronics L121, which can hardly be removed under similar conditions. ${ }^{[42]}$ The solvent uptake of the foam was assessed by determining the weight and volume of disc-shaped specimens in wet state and setting it into relation to the foams initial dry state. Water, ethanol, acetone, $n$-pentanol and toluene were tested (Fig. 3). In ethanol, acetone and $n$-pentanol swelling was with $3 \pm 0.5 \%, 6 \pm 0.7 \%$ and $2 \pm 0.3 \%$ rather low, indicating a predominant accommodation of solvents in the voids. In toluene pronounced swelling of $419 \pm 35 \mathrm{v} \%$ was noted and toluene uptake was found to be $1300 \pm 250 \mathrm{w} \%$. A similar value was found for a foam prepared with $7 \mathrm{w} \%$ Pluronics L121 $(1148 \pm 19 \mathrm{w} \%) .{ }^{[42]}$ Drying the specimens until constant weight was reached and repeating the immersion procedure lead to a decrease of the solvent uptake capability with the cycle number. The trend is most pronounced for the repeated immersion into toluene but is also noticeable in the case of the other solvents under investigation. In particular in the case of toluene, this behavior can be best explained by a destruction of the foams structure upon drying (Fig. 3). ${ }^{[2,44]}$ In the other cases no visual deformation of the specimens upon drying could be noted and the original sizes and shapes of the specimens were recovered.

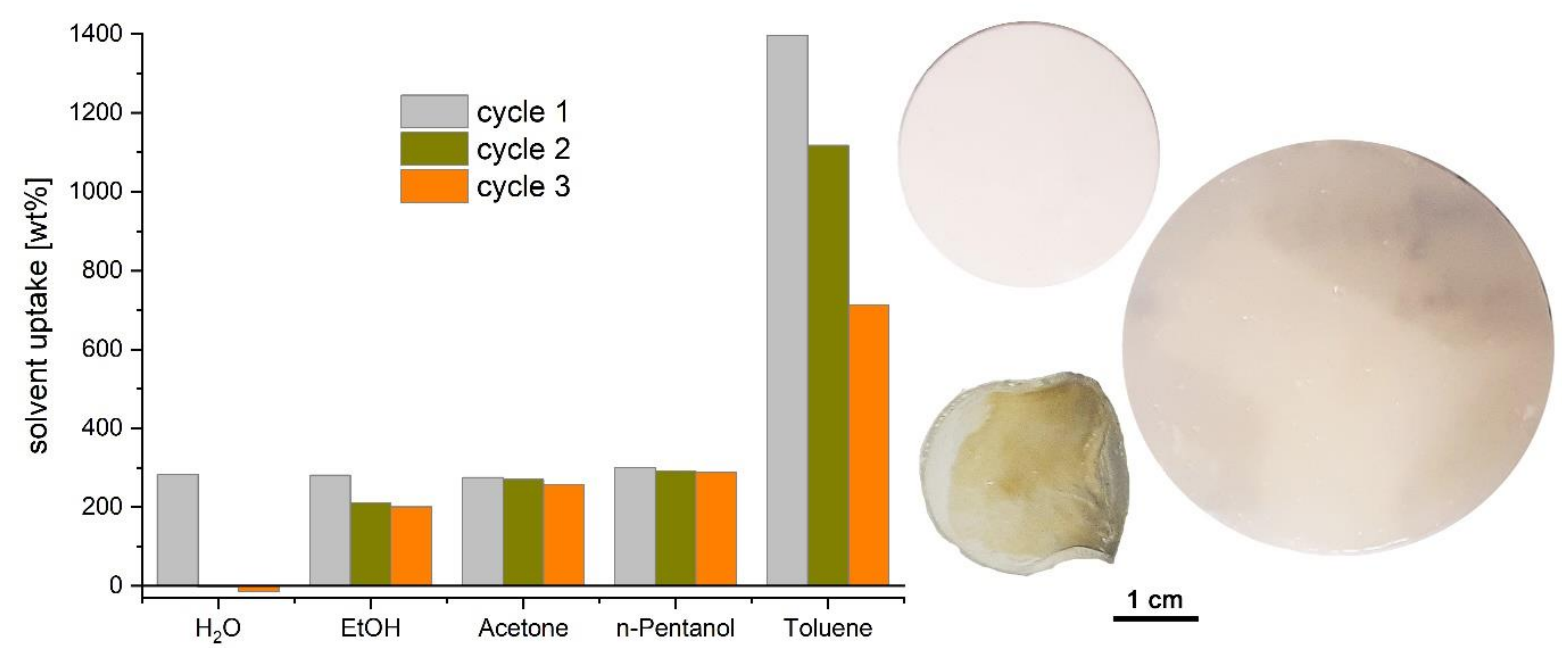

Figure 3. left) mass increase upon immersion into solvents; between cycles the specimens were dried until constant weight was reached; right) photographs of a specimen immersed with npentanol (above); with toluene (below, right) and after deswelling the toluene immersed specimen (below, left).

Particularly interesting is the specimens' behavior when immersed into water. In the first cycle $282 \pm 10 \mathrm{w} \%$ water was absorbed but in the second and third cycle no water uptake could be observed. The foam floated on the water surface and even when the specimen was submersed (using an additional weight) no water uptake took place. However, uptake of n-pentanol 
occurred as expected so that a change of morphology of the foams could be ruled out as the reason for the exclusion of water. It is hypothesized that a nonpolar foam surface forms during the first cycle (in which water is still taken up to considerable extend). Presumably, the sodium carboxylate heads residing at the surface are transformed into less polar carboxylic acid groups (the water from the first cycle is with $\mathrm{pH} 8$ slightly alkaline). However, this process is not reversible because also tries to adsorb $1 \mathrm{M} \mathrm{NaOH}$ solution were unsuccessful. Cleansing away of $\mathbf{2}$ is also unlikely since the surfactant is not water soluble (neither in its basic nor in its acidic form). Accordingly, it is suggested that carboxylic acid groups are removed from the surface by accommodation in the polymer phase. This phenomenon is known as hydrophobic recovery ${ }^{[43]}$ and is the most likely explanation for the resistance of the foams to absorb water. The complete exclusion of water by macroporous pDCPD foams prepared with non-ionic surfactants is unprecedented. ${ }^{[42,44]}$ In light of the results presented here, it seems plausible that conventionally used non-ionic surfactants stay at the polymer surface and conserve a certain surface polarity allowing for water-uptake.

\section{Conclusions}

In summary, we herein improved the protocol for the degradation of natural rubber glove waste by Cross Metathesis with alkyl acrylates in terms of catalyst costs. An upstream mechanothermal predegradation step of the natural rubber glove waste resulted in a homogenous natural rubber solution in toluene, which can be directly used in the Cross Metathesis step. Using this pretreatment allowed for substituting the previously used catalyst M510 for the cheaper catalyst $\mathbf{M 2 0 2}$ and at the same time, a reduction of the catalyst loading to $0.1 \mathrm{~mol} \%$ in respect to natural rubber double bond was achieved. The resulting isoprene oligomers containing $\alpha, \beta$-unsaturated ester groups as one end-group were then saponified with sodium hydroxide resulting an cyclohexane soluble mixture of ionic amphiphiles featuring different oligo(isoprene) chain lengths with an average number of repeating numbers of 7 . Furthermore, side reactions of the enoate groups occurred. The such obtained amphiphile mixture was used as the surfactant for stabilizing water in dicyclopentadiene emulsions and curing of the continuous dicyclopentadiene phase by Ring-opening Metathesis Polymerization resulted in the formation of opened macroporous poly(dicyclopentadiene) foams constituting the first example of using a ionic surfactant for high internal phase emulsion templating of this polymer. The use of the ionic surfactant allows for the preparation of pDCPD foams which are resistant to absorb water, a property hitherto not accessible for this type of materials. 


\section{Experimental Section}

\section{Materials and Methods}

NR Gloves (Kimberly-Clark Professional KIMTECH* PFE), DCPD (adcr), M202 ([1,3-Bis(2,4,6trimethylphenyl)-2-imidazolidinylidene]dichloro(3-phenyl-1H-inden-1-

ylidene)(tricyclohexylphosphine) ruthenium(II), UMICORE), ethanol (Aldrich), acetone (Aldrich), $n$-pentanol (Fisher Scientific), toluene (Aldrich), methyl acrylate (TCI) and methyl crotonate (Aldrich) were used as received.

SEC chromatographic analysis was performed on a WGE Dr. Bures SEC3010 with THF as eluent $(1 \mathrm{~mL} / \mathrm{min})$ and RI-detection. Poly(styrene) standards were used for calibration.

NMR-spectra were measured on a Bruker Avance $300 \mathrm{MHz}$ equipped with an auto sampler. ${ }^{1} \mathrm{H}-$ NMR spectra were measured at $300.36 \mathrm{MHz}$ and ${ }^{13} \mathrm{C}-\mathrm{NMR}$ at $75.53 \mathrm{MHz}$ at a temperature of $25^{\circ} \mathrm{C}$. NMR samples were prepared using $\mathrm{CDCl}_{3}$ from Eurisotop. The ${ }^{1} \mathrm{H}$-NMR spectra were calibrated at the solvent peak at $7.26 \mathrm{ppm}$ respectively $77.16 \mathrm{ppm}$ in the case of ${ }^{13} \mathrm{C}-\mathrm{NMR}$. The relaxation time was set to $5 \mathrm{~s}$ in order to grant full relaxation and thereby a more accurate chain length determination.

SEM images were taken with a Jeol JSM-5410 Microscope at an acceleration voltage of $5000 \mathrm{~V}$ by Robert Saf. In order to get non-deformed features visualized, the sample monoliths were oxidized and broken. ${ }^{[21]}$ Before taking the images, samples were sputtered with gold using a Biorad Goldcoating system.

IR spectra were taken on an ALPHA-P FT-IR Spectrometer from Bruker with a diamond based ATR module.

The microscope images were taken on an Olympus BX60 microscope connected to an Olympus E250 camera.

Filtration was performed using a Büchner funnel $(\varnothing 4 \mathrm{~cm})$ with $\mathrm{MN} 85 / 70$ filter paper from Macherey-Nagel and vacuum from a water jet pump was applied during filtration.

\section{Syntheses}

\section{Thermal pre-degradation of natural rubber}

$18.21 \mathrm{~g}(267.3 \mathrm{mmol}) \mathrm{NR}$ gloves were cut into small pieces $(\sim 1 \times 1 \mathrm{~cm})$ and toluene $(500 \mathrm{~mL})$ was added. The reaction mixture was heated to $110^{\circ} \mathrm{C}$ and was stirred for $48 \mathrm{~h}$ with a mechanical stirrer (200 rpm), resulting in a polyisoprene solution featuring some suspended particles. The particles were removed by centrifugation at $4000 \mathrm{rpm}$ over $20 \mathrm{~min}$ and subsequent filtration with filter paper of a pore size of $0.6 \mu \mathrm{m}$. Toluene was removed and the product is dried under vacuum. Yield: 14.17 $\mathrm{g}\left(77.8 \%, \mathrm{M}_{\mathrm{n}}=1300 \mathrm{~g} / \mathrm{mol}, \mathrm{Ð}=2.2\right)$.

ATR-IR: $v=2961,2919,2853,1712,1662,1446,1373,1307,1241,1126,1084,1038,1012$, $887,834,729,692,502 \mathrm{~cm}^{-1}$.

\section{Cross-metathesis of pre-degraded natural rubber with methyl acrylate yielding oligomers 1}

A stock solution of pre-degraded polyisoprene in toluene was prepared $(20 \mathrm{mg} / \mathrm{mL}) .55 \mathrm{~mL}$ (1 eq., $16.1 \mathrm{mmol}$ ) of this stock solution was placed in a $100 \mathrm{~mL}$ Schlenk-flask. $7.32 \mathrm{~mL}$ (5 eq., $80.8 \mathrm{mmol}$ ) of methyl acrylate was added, and alternately vacuum and $\mathrm{N}_{2}$ flow were applied three times. After bubbling $\mathrm{N}_{2}$ through the solution for $15 \mathrm{~min}$, the mixture was heated up to $80{ }^{\circ} \mathrm{C}$. $15.3 \mathrm{mg}(0.1 \mathrm{~mol} \%, 16.1 \mu \mathrm{mol})$ of catalyst $\mathbf{M 2 0 2}$ dissolved in $1.53 \mathrm{~mL}$ toluene were added. The reaction was held at $80^{\circ} \mathrm{C}$ for $22 \mathrm{~h}$ after addition of the catalyst solution under $\mathrm{N}_{2}$ counter flow. The volatiles were removed under vacuum and the residual brown sludge was purified via column chromatography (ethyl acetate:cyclohexane $=1: 50$, silica: $35 \mathrm{~mL}$ ). The solvent was removed at the rotary evaporator and the product, a yellow oil, was dried under vacuum. Yield: $855 \mathrm{mg}$ (67\%, chain length: 6.5).

${ }^{1} \mathrm{H}-\mathrm{NMR}\left(300 \mathrm{MHz}, 25^{\circ} \mathrm{C}, \mathrm{CDCl}_{3}\right): \delta=6.94\left(\mathrm{dt}, 0.88 \mathrm{H},-\mathrm{CH}_{\text {trans }}=\mathrm{CH}-\mathrm{COOCH}_{3}\right) ; 6.21(\mathrm{~m}, 0.12 \mathrm{H}$, $\left.-\mathrm{CH}_{\text {cis }}=\mathrm{CH}-\mathrm{COOCH}_{3}\right) ; 5.83\left(\mathrm{~d},{ }^{3} \mathrm{~J}=15.7 \mathrm{~Hz}, 1 \mathrm{H},-\mathrm{CH}_{\text {trans }}=\mathrm{CH}-\mathrm{COOCH}_{3}-\right.$ submersed $-\mathrm{CH}_{\text {cis }}=\mathrm{CH}-$ 
$\left.\mathrm{COOCH}_{3}\right) ; 5.30-5.00,\left(\mathrm{~m}, 6.48 \mathrm{H},-\mathrm{C}\left(\mathrm{CH}_{3}\right)=\mathrm{CH}-\right) ; 4.70,4.68\left(\mathrm{~s}, 2 \mathrm{H},-\mathrm{C}\left(\mathrm{CH}_{3}\right)=\mathrm{CH}_{2}\right) ; 3.72(\mathrm{~s}, 3 \mathrm{H}$, $\left.\mathrm{COOCH}_{3}\right) ; 2.34-1.92\left(\mathrm{~m}, 30.1 \mathrm{H},-\mathrm{CH}_{2}-\mathrm{CH}_{2}-\right) ; 1.72,1.68\left(\mathrm{~s}, 22.4 \mathrm{H},-\mathrm{C}\left(\mathrm{CH}_{3}\right)=\mathrm{CH}-,-\mathrm{C}\left(\mathrm{CH}_{3}\right)=\mathrm{CH}_{2}\right)$. ${ }^{13} \mathrm{C}\left\{{ }^{1} \mathrm{H}\right\}$-NMR $\left(75 \mathrm{MHz}, 25{ }^{\circ} \mathrm{C}, \mathrm{CDCl}_{3}\right): \delta=167.1\left(-\mathrm{COOCH}_{3}\right) ; 149.2,146.0,145.7(-\mathrm{CH}=\mathrm{CH}-$ $\left.\mathrm{COOCH}_{3},-C\left(\mathrm{CH}_{3}\right)=\mathrm{CH}_{2}\right) ; 135.3,135.1,133.8\left(-C\left(\mathrm{CH}_{3}\right)=\mathrm{CH}-\right) ; 126.3,126.1,125.4,125.2,125.0$ $\left(-\mathrm{C}\left(\mathrm{CH}_{3}\right)=\mathrm{CH}-\right) ; 121.2\left(-\mathrm{CH}=\mathrm{CH}-\mathrm{COOCH}_{3}\right) ; 110.1,109.9\left(-\mathrm{C}_{\left(\mathrm{CH}_{3}\right)}=\mathrm{CH}_{2}\right) ; 51.5\left(-\mathrm{COOCH}_{3}\right) ; 38.2$,

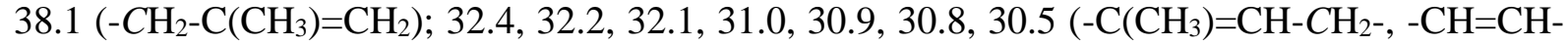
$\left.\mathrm{CH}_{2^{-}}\right)$; 26.5, 26.3, $26.2\left(-\mathrm{CH}_{2}-\mathrm{C}\left(\mathrm{CH}_{3}\right)=\mathrm{CH}-\right)$; 23.5, 23.4, $22.6\left(-\mathrm{C}\left(\mathrm{CH}_{3}\right)=\mathrm{CH}-,-\mathrm{C}\left(\mathrm{CH}_{3}\right)=\mathrm{CH}_{2}\right)$. ATR-IR: $v=3380,2958,2921,2854,1728,1655,1491,1443,1372,1309,1259,1186,1082$, $1026,965,886,803,745,708,667,570,490 \mathrm{~cm}^{-1}$.

\section{Saponification of semi-telechelic polyisoprene oligomers yielding stabilizer 2}

$855 \mathrm{mg}$ ( 1 eq., $1.44 \mathrm{mmol}$ ) of the oligomers 1 was dissolved in $150 \mathrm{~mL}$ of ethanol and $4 \mathrm{~mL}$ (53.1 eq., $76.5 \mathrm{mmol}) \mathrm{NaOH}_{\mathrm{aq}} 50 \%$ was added. The reaction mixture was stirred for $4 \mathrm{~h}$ at $75{ }^{\circ} \mathrm{C}$. Afterwards, volatiles were removed in vacuum and the residue was redissolved in $100 \mathrm{~mL}$ cyclohexane. Extraction with $2 \times 50 \mathrm{~mL}$ of water, subsequent drying of the organic phase over $\mathrm{Na}_{2} \mathrm{SO}_{4}$, removal of the solvent and drying in vacuum gave the saponified oligomers. Yield: 760 mg $(72 \%$, chain length: 7.1$)$.

$\delta=7.07\left(\mathrm{dt}, 0.5 \mathrm{H},-\mathrm{CH}_{\text {trans }}=\mathrm{CH}-\mathrm{COONa}\right) ; 6.33\left(\mathrm{~m}, 0.1 \mathrm{H},-\mathrm{CH}_{c i s}=\mathrm{CH}-\mathrm{COONa}\right) ; 5.86\left(\mathrm{~d},{ }^{3} \mathrm{~J}=\right.$ $15.7 \mathrm{~Hz}, 0.6 \mathrm{H},-\mathrm{CH}_{\text {trans }}=\mathrm{CH}-\mathrm{COONa}-$ submersed $\left.-\mathrm{CH}_{\text {cis }}=\mathrm{CH}-\mathrm{COONa}\right) ; 5.55$ (bs, $0.2 \mathrm{H},-\mathrm{CH}_{2}-$

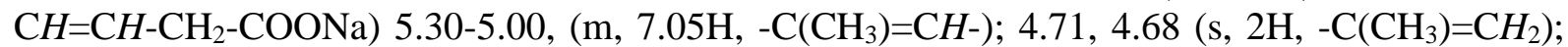
$3.72,3.56\left(\mathrm{bm}, 0.9 \mathrm{H}, \mathrm{CHOCH}_{2} \mathrm{CH}_{3}\right) ; 3.20,3.10,2.77\left(\mathrm{~m}, 0.4 \mathrm{H},-\mathrm{CH}_{2}-\mathrm{CH}=\mathrm{CH}-\mathrm{CH}_{2}-\mathrm{COONa}\right)$; 2.56-2.00 (m, 36.2H, $\left.-\mathrm{CH}_{2}-\mathrm{CH}_{2}-\right) ; 1.72,1.68\left(\mathrm{~s}, 24.4 \mathrm{H},-\mathrm{C}\left(\mathrm{CH}_{3}\right)=\mathrm{CH}-,-\mathrm{C}\left(\mathrm{CH}_{3}\right)=\mathrm{CH}_{2}\right) ; 1.23(\mathrm{t}$, $\left.0.9 \mathrm{H}, \mathrm{OCH}_{2} \mathrm{CH}_{3}\right)$.

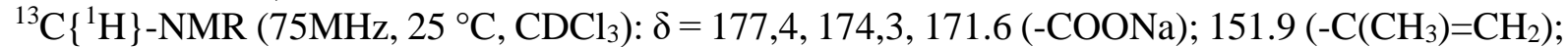
$146.0(-\mathrm{CH}=\mathrm{CH}-\mathrm{COONa}) ; 135.4,135.1,133.5\left(-\mathrm{C}\left(\mathrm{CH}_{3}\right)=\mathrm{CH}-\right) ; 126.5,125.4,125.2,125.0(-$ $\left.\mathrm{C}\left(\mathrm{CH}_{3}\right)=\mathrm{CH}-\right) ; 120.8(-\mathrm{CH}=\mathrm{CH}-\mathrm{COOH}) ; 109.9\left(-\mathrm{C}\left(\mathrm{CH}_{3}\right)=\mathrm{CH}_{2}\right) ; 75,7,64.9\left(\mathrm{CHOCH}_{2} \mathrm{CH}_{3}\right) ; 38.25$ $\left(-\mathrm{CH}_{2}-\mathrm{C}\left(\mathrm{CH}_{3}\right)=\mathrm{CH}_{2}\right) ; 32.4,32.2,31.0,30.3,29.8\left(-\mathrm{C}\left(\mathrm{CH}_{3}\right)=\mathrm{CH}-\mathrm{CH}_{2-},-\mathrm{CH}=\mathrm{CH}_{-} \mathrm{CH}_{2-}\right) ; 26.5,26.3$ $\left(-\mathrm{CH}_{2}-\mathrm{C}\left(\mathrm{CH}_{3}\right)=\mathrm{CH}-\right) ; 23.6,23.4,22.6\left(-\mathrm{C}\left(\mathrm{CH}_{3}\right)=\mathrm{CH}-,-\mathrm{C}\left(\mathrm{CH}_{3}\right)=\mathrm{CH}_{2}\right)$.

ATR-IR of the sodium carboxylates: $v=3368,2958,2921,2854,1648,1554,1493,1444,1377$, $1307,1238,1083,996,975,926,883,826,728,694,671,641,583,516 \mathrm{~cm}^{-1}$.

\section{Preparation and characterization of the foams}

$700 \mathrm{mg}$ (1.04 mmol) of the stabilizer (2), $9.84 \mathrm{~g}$ (71.5 eq., $74.4 \mathrm{mmol})$ DCPD and $100 \mu \mathrm{L}$ toluene were placed in a $250 \mathrm{~mL}$ three necked flask and a homogenous solution was formed under stirring with a mechanical stirrer. $600 \mathrm{mg}$ (9.90 eq., $10.3 \mathrm{mmol}) \mathrm{NaCl}$, dissolved in $40 \mathrm{~mL}$ of water, were added dropwise. The resulting white, viscous emulsion was stirred for $1 \mathrm{~h}$ at $400 \mathrm{rpm}$ before adding $4.7 \mathrm{mg}(66.7 \mathrm{ppm}, 5.0 \mu \mathrm{mol})$ of $\mathbf{M 2 0 2}$ dissolved in toluene $(200 \mu \mathrm{L})$. The reaction mixture was poured into Teflon molds $\left(\varnothing 30 \mathrm{~mm} \times 2 \mathrm{~mm}\right.$ ) and placed in the drying cabinet at $80^{\circ} \mathrm{C}$ for $3 \mathrm{~h}$. The resulting white, solid monoliths were then submersed in acetone for $15 \mathrm{~min}$ and dried at room temperature in vacuum.

\section{Swelling/deswelling of polyHIPE disks}

Disks of a height of $2 \mathrm{~mm}$ and diameter of $30 \mathrm{~mm}$ were prepared as described above. Five solvents of different polarities, namely water $(\varepsilon=80)$, ethanol $(\varepsilon=25)$, acetone $(\varepsilon=21)$, n-pentanol $(\varepsilon=15)$ and toluene $(\varepsilon=2.4)$ were placed in a different beakers. The disks were immersed into the solvents for $24 \mathrm{~h}$ for swelling. The swollen disks were then placed in acetone for $15 \mathrm{~min}$ and left to dry for $24 \mathrm{~h}$ for deswelling. The swelling and deswelling was performed three times for every disk and their weight and dimensions were recorded for each step. 
Void-, window- and bubble-size evaluation

In order to monitor the HIPEs stability and to characterize the polyHIPE, the void-, window- and bubble-sizes were measured. Therefore, in case of the HIPE, microscope images were taken. At least five different images were evaluated thereby using at least one hundred measurements per image to determine median droplet diameters and their distribution.

In the case of the foams, sample monoliths were oxidized and subsequently broken according to literature. ${ }^{[22]}$ After sputtering gold onto the surface SEM images were recorded on a Jeol JSM-5410 microscope using an acceleration voltage of $5000 \mathrm{~V}$. At least 100 void and window diameters were measured for determining the median void and window diameters as well as their distributions.

Supporting Information containing NMR and IR spectra as well as optical and scanning electron micrographs is available as separate file.

Acknowledgements: Funding by the Christian Doppler Research Association (Austrian Federal Ministry for Digital and Economic Affairs and the National Foundation for Research, Technology and Development) and the lead-project LP-03 of Graz University of Technology is kindly acknowledged. We thank R. Saf for SEM measurements and Umicore for providing the initiator.

\section{References}

\footnotetext{
${ }^{1}$ Association of Natural Rubber Producing Countries, Rubber and Plastics News 2018, Jan. 22, 2018.

${ }^{2}$ Reducing of Energy Consumption by Improving the Reclaiming Technology in Autoclave of a Rubber Wastes. Dobrotă, D.; Dobrotă, G. Energies 2019, 12, 1460. DOI: 10.3390/en12081460

${ }^{3}$ Current progress in waste tire rubber devulcanization. Saputra, R.; Walvekar, R.; Khalid, M.; Mubarak, N. M.; Sillanpää, M. Chemosphere 2021, 265, 129033. DOI: j.chemosphere.2020.129033

${ }^{4}$ Devulcanisation and reclaiming of tires and rubber by physical and chemical processes: A review. Bockstal, L.; Berchem, T.; Schmetz, Q.; Richel, A. J. Clean. Prod. 2019, 236, 117574. DOI: 10.1016/j.jclepro.2019.07.049
}

${ }^{5}$ Sustainable rubbers and rubber additives. Sarkar, P.; Bhowmick, A. K. J. Appl. Polym. Sci. 2017, 135, 45701. DOI: $10.1002 / a p p .45701$

${ }^{6}$ Olefin metathesis meets rubber chemistry and technology. Leimgruber, S.; Trimmel, G. Monatsh. Chem. 2015, 146, 1081-1097. DOI: 10.1007/s00706-015-1501-0

${ }^{7}$ Olefin Metathesis Reaction in Rubber Chemistry and Industry and Beyond. Liu, P.; Ai, C. Ind. Eng. Chem. Res. 2018, 57, 3807-3820. DOI: 10.1021/acs.iecr.7b03830

${ }^{8}$ Ethenolysis: A Green Catalytic Tool to Cleave Carbon-Carbon Double Bonds. Bidange, J.; Fischmeister, C.; Bruneau, C. Chem. Eur. J. 2016, 22, 12226-12244. DOI: 10.1002/chem.201601052

${ }^{9}$ On the ethenolysis of natural rubber and squalene. Wolf, S.; Plenio, H. Green Chem. 2011, 13, 20082012. DOI: $10.1039 / \mathrm{C} 1 \mathrm{GC} 15265 \mathrm{C}$

${ }^{10}$ Simple access to alkoxysilyl telechelic polyolefins from ruthenium-catalyzed cross-metathesis depolymerization of polydienes. Michel, X.; Fouquay, S.; Michaud, G.; Simon, F.; Brusson, J.-M.; Carpentier, J.-F.; Guillaume, S. M. Eur. Polym. J. 2017, 96, 403-413. DOI: $\underline{10.1016 / j . e u r p o l y m j .2017 .09 .027}$

${ }^{11}$ One-Pot Synthesis of Natural Rubber-Based Telechelic cis-1,4-Polyisoprenes and Their Use To Prepare Block Copolymers by RAFT Polymerization. Saetung, N.; Campistron, I.; Pascual, S.; Pilard, J.-F.; Fontaine, L. Macromolecules 2011, 44, 784-794. DOI: 10.1021/ma102406w

${ }^{12}$ On the ethenolysis of end-of-life tire granulates. Wolf, S.; Plenio, H. Green Chem. 2013, 15, 315-319. DOI: $10.1039 / \mathrm{C} 2 \mathrm{GC} 36417 \mathrm{D}$ 
${ }^{13}$ Controlled Metathetic Depolymerization of Natural Rubber in Ionic Liquids: From Waste Tires to Telechelic Polyisoprene Oligomers. Mouawia, A.; Nourry, A.; Gaumont, A.-C.; Pilard, J. F.; Dez, I. ACS Sustainable Chem. Eng. 2017, 5, 696-700. DOI: 10.1021/acssuschemeng.6b01777

${ }^{14}$ Converting natural rubber waste into Ring-opening Metathesis polymers with oligo-1,4-cis-isoprene sidechains. Abbas, M.; Neubauer, M.; Slugovc, C. Polym. Chem. 2018, 9, 1763-1766. DOI: 10.1039/C8PY00233A

${ }^{15}$ A quantitative kinetic theory of emulsion type, I. Physical chemistry of the emulsifying agent. Davies, J. T. Proceedings of the International Congress of Surface Activity, 1957, 426-438.

${ }^{16}$ Emulsion Templating: Porous Polymers and Beyond. Zhang, T.; Sanguramath R. A.; Israel S.; Silverstein, M. S. Macromolecules 2019, 52, 5445-5479. DOI: 10.1021/acs.macromol.8b02576

${ }^{17}$ Emulsion-templated polymers: Contemporary contemplations. Silverstein, M. S. Polymer 2017, 126, 261-282. DOI: 10.1016/j.polymer.2017.07.046

${ }^{18}$ Preparation and functionalisation of emulsion-derived microcellular polymeric foams (polyHIPEs) by ring-opening metathesis polymerisation (ROMP). Deleuze, H.; Faivre, R.; Herroguez, V. Chem. Commun. 2002, 2822-2823. DOI: 10.1039/B208832K

${ }^{19}$ Ring opening polymerisation of highly concentrated inverse emulsions to obtain microcellular foams. Benmachou, K.; Deleuze, H.; Herroguez, V. React. Funct. Polym. 2003, 55, 211-217. DOI: 10.1016/S1381-5148(02)00248-1

${ }^{20}$ Ring-opening Metathesis Polymerisation derived poly(dicyclopentadiene) based materials. Kovačič, S.; Slugovc, C. Mater. Chem. Front. 2020, 4, 2235-2255. DOI: 10.1039/D0QM00296H

${ }^{21}$ Inherently Reactive polyHIPE Material from Dicyclopentadiene. Kovacic, S.; Krajnc, P.; Slugovc, C. Chem. Commun. 2010, 46, 7504-7506. DOI: 10.1039/C0CC02610G

${ }^{22}$ Ring Opening Metathesis Polymerisation of emulsion templated dicyclopentadiene giving open porous materials with excellent mechanical properties. Kovačič, S.; Jeřabek, K.; Krajnc, P.; Slugovc, C. Polym. Chem. 2012, 3, 325-328. DOI:10.1039/C2PY00518B;

${ }^{23}$ On the Mechanical Properties of HIPE Templated Macroporous poly(Dicyclopentadiene) Prepared with Low Surfactant Amounts. Kovačič, S.; Matsko, N. B.; Jeřabek, K.; Krajnc, P.; Slugovc, C. J. Mater. Chem. A 2013, 1, 487-490. DOI: 10.1039/C2TA00546H;

${ }^{24}$ Tailoring the Mechanical and Thermal Properties of Dicyclopentadiene PolyHIPEs with the Use of a Comonomer. Mert, E. H.; Slugovc, C.; Krajnc, P. Express Polym. Lett. 2015, 9, 344-353. DOI: 10.3144/expresspolymlett.2015.32

${ }^{25}$ Strength versus Toughness of Emulsion Templated Poly(Dicyclopentadiene) Foams. Kovačič, S.; Žagar, E.; Slugovc, C. Polymer, 2019, 169, 58-65. DOI: 10.1016/j.polymer.2019.02.045

${ }^{26}$ Supercritical $\mathrm{CO}_{2}$ Mediated Functionalization of Highly Porous Emulsion-Derived Foams: $\mathrm{scCO}_{2}$ Absorption and Epoxidation. Trupej, N.; Novak, Z.; Knez, Ž.; Slugovc, C.; Kovačič, S. J. CO2 Util. 2017, 21, 336-341. DOI: 10.1016/j.jcou.2017.07.024;

27 Inverse electron demand Diels-Alder (iEDDA) functionalisation of macroporous poly(dicyclopentadiene) foams. Knall, A.-C.; Kovačič, S.; Hollauf, M.; Reishofer, D. P.; Saf, R.; Slugovc, C. Chem. Commun. 2013, 49, 7325-7327. DOI: 10.1039/C3CC42925C

28 Air Activated Self-Decontaminating Polydicyclopentadiene PolyHIPE Foams for Rapid Decontamination of Chemical Warfare Agents. McGann, C. L.; Daniels, G. C.; Giles, S. L.; Balow, R. B.; Miranda-Zayas, J. L.; Lundin, J. G.; Wynne, J. H. Macromol. Rapid Commun. 2018, 39, 1800194. DOI: $\underline{10.1002 / \mathrm{marc} .201800194}$

${ }^{29}$ Fast oxygen scavenging of macroporous poly(norbornadiene) prepared by Ring-opening Metathesis Polymerization. Vakalopoulou, E.; Borisov, S. M.; Slugovc, C. Macromol. Rapid Commun. 2020, 41, 1900581. DOI: $10.1002 /$ marc.201900581

${ }^{30}$ Covalent incorporation of the surfactant into high internal phase emulsion templated polymeric foams. Kovačič, S.; Preishuber-Pflügl, F.; Pahovnik, D.; Žagar, E.; Slugovc, C. Chem. Commun. 2015, 51, 7225-7228. DOI: 10.1039/C4CC09199J 
${ }^{31}$ The use of an emulsion templated microcellular poly(dicyclopentadiene-co-norbornene) membrane as separator in lithium-ion batteries. Kovačič, S.; Kren, H.; Krajnc, P.; Koller, S.; Slugovc, C. Macromol. Rapid Commun. 2013, 34, 581-587. DOI: 10.1002/marc.201200754

${ }^{32}$ Macroporous poly(dicyclopentadiene) $\gamma \mathrm{Fe}_{2} \mathrm{O}_{3} / \mathrm{Fe}_{3} \mathrm{O}_{4}$ nanocomposite foams by high internal phase emulsion templating. Kovačič, S.; Matsko, N. B.; Ferk, G.; Slugovc, C. J. Mater. Chem. A. 2013, 1, 7971-7978. DOI: $10.1039 /$ C3TA11402C

${ }^{33}$ Macroporous ZnO Foams by High Internal Phase Emulsion Technique: Synthesis and Catalytic Activity. Kovačič, S.; Anžlovar, A.; Erjavec, B.; Kapun, G.; Matsko, N. B.; Zigon, M.; Zagar, E.; Pintar, A.; Slugovc, C. ACS Appl. Mater. Interfaces 2014, 6, 19075-19081. DOI: 10.1021/am5050482

${ }^{34}$ Photocatalytic Activity of Titania/Polydicyclopentadiene PolyHIPE Composites. Yüce, E.; Mert, E. H.; Krajnc, P.; Parın, F. N.; San, N.; Kaya, D.; Yıldırım, H. Macromol. Mater. Eng. 2017, 302, 1700091. DOI: $10.1002 /$ mame.201700091

${ }^{35}$ Influence of nanoparticles and antioxidants on mechanical properties of titania/polydicyclopentadiene polyHIPEs: A statistical approach. Yüce, E.; Krajnc, P.; Mert, H. H.; Mert, E. H. Appl. Polym. Sci. 2019, 136, 46913: DOI: 10.1002/app.46913

${ }^{36}$ Synthesis and Catalytic Performance of Hierarchically Porous MIL-100(Fe)@polyHIPE Hybrid Membranes. Kovačič, S.; Mazaj, M.; Jeselnik, M.; Pahovnik, D.; Žagar, E.; Slugovc, C.; Zabukovec Logar, N. Macromol. Rapid Commun. 2015, 36, 1605-1611. DOI: 10.1002/marc.201500241

${ }^{37}$ A facile strategy towards a highly accessible and hydrostable MOF-phase within hybrid polyHIPEs through in situ metal-oxide recrystallization. Mazaj, M.; Zabukovec Logar, N.; Žagar, E.; Kovačič, S. J. Mater. Chem. A 2017, 5, 1967-1971. DOI: 10.1039/C6TA10886E

${ }^{38}$ Ring-Opening Metathesis Polymerization Derived Hierarchically Porous Carbon-Foams. Kovacic, S.; Matsko, N. B.; Gruber, K.; Koller, S.; Slugovc, C. ChemRxiv 2020, Preprint. DOI: $\underline{10.26434 / \text { chemrxiv.11674041.v1 }}$

${ }^{39}$ Stabilization of Lipase in Polymerized High Internal Phase Emulsions. Andler, S. M.; Goddard, J. M. J. Agric. Food Chem. 2018, 66, 3619-3623. DOI: 10.1021/acs.jafc.8b00894

${ }^{40}$ The preparation and reactions of enolate anions derived from $\alpha, \beta$-unsaturated esters. Rathke, M. W.; Sullivan, D. Tetrahedron Lett. 1972, 13, 4249-4252. DOI: 10.1016/S0040-4039(01)94287-X

${ }^{41}$ Two commercially available initiators for the retarded ring-opening metathesis polymerization of dicyclopentadiene. Leitgeb, A.; Wappel, J.; Urbina-Blanco, C. A.; Strasser, S.; Wappl, C.; Cazin, C. S. J.; Slugovc, C. Monatsh. Chem. 2014, 145, 1513-1517. DOI: 10.1007/s00706-014-1249-y

42 The effects of enhancing the crosslinking degree in high internal phase emulsion templated poly(dicyclopentadiene). Vakalopoulou, E.; Slugovc, C. Macromol. Chem. Phys. 2019, 220, 1900423. DOI: $10.1002 / \mathrm{macp} .201900423$

${ }^{43}$ Towards understanding hydrophobic recovery of plasma treated polymers: Storing in high polarity liquids suppresses hydrophobic recovery. Bormashenko, E.; Chaniel, G.; Grynyov, R. Appl. Surf. Sci. 2013, 273, 549-553. DOI: 10.1016/j.apsusc.2013.02.078

${ }_{44}$ Macroporous Polyolefin Membranes from Dicyclopentadiene High Internal Phase Emulsions: Preparation and Morphology Tuning. Kovačič, S.; Preishuber-Pflügl, F.; Slugovc, C. Macromol. Mater. Eng. 2014, 299, 843-850. DOI: 10.1002/mame.201300400 